\title{
Practice Reflections
}

\section{Improving outcomes for 'failing' students through the use of presentations}

\section{Jenny Peddar ${ }^{1}$ and Cher Brazier ${ }^{2}$}

\begin{abstract}
Over recent years there has been an increasing use of presentations for students who are struggling in, or have failed a practice placement on the qualifying social work programmes. This has often been set up following the student having attended a practice consultation panel at the request of member of the students' placement team. The presentations are aimed at improving the students' understanding of the issues that have led to their difficulties on placement and are therefore specific to that student. Some students have been asked to prepare just one presentation whilst others have been given up to 4 titles. The experience of the university placement team, and the practice agencies that offer a repeat placement is that it has led to an improvement in the outcome for many students as this has led to greater understanding of issues and therefore preparation for the repeat placement. Some of the students concerned have chosen at the end of the process of undertaking presentations that they will not complete the professional award and this decision has been clearer and based on better quality evidence and thinking. This paper considers the process, outcomes and potential gains of this system.
\end{abstract}

Keywords: failing students, practice placements, presentations, outcomes

1. Senior Lecturer, Social Work Professional Area, University of Portsmouth

2. Practice Learning Coordinator / Approved Mental Health Practitioner Learning and Development, City of Portsmouth

Address for correspondence: Jenny Peddar, Social Work Professional Area, School of Health Sciences and Social Work, University of Portsmouth, James Watson West, 2 King Richard 1st Rd, Portsmouth. PO1 2FR. jenny.peddar@port.ac.uk

80 J. of Practice Teaching \& Learning 11(1), pp.80-88. DOI: 10.1921/ 175951511X651931. @ w\&b 


\section{Introduction}

The University of Portsmouth has used presentations within qualifying training courses for many years. These include group and individual presentations by students, and the audience may comprise one or two academic staff, service users, a practice placement team including the practice assessor and tutor, or a group of students. The rationale for using presentations varies from preparing students for their future roles in practice in addition to providing a variety of means of assessment rather than relying on written work and essays. Presentations have been used on all of our programmes at pre and post qualifying levels and this includes both undergraduate and postgraduate students.

There have been a number of developments and changes over recent years as the qualification moved to graduate format and this was mirrored by changes in regulation. There had been a requirement by CCETSW (Central Council for the Education and Training of Social Workers) for the use of second opinion practice teachers where a student was experiencing difficulties in a practice placement (CCETSW, 1989). This led to the development of processes in individual institutions that aimed to ensure clear decisions regarding the suitability of students for the profession and allow equity and fairness in the assessment processes. The value of these processes was acknowledged by a number of authors over the years and the removal of the requirements created consternation amongst practice educators from the first suggestion of this change. (McColgan and Douglas, 1995; Barron, 2004).

As a response to the changes in requirement, and also the increasing difficulty in finding people able to undertake the second opinion role at short notice, the Wessex region developed a process of practice consultation panels as a replacement to the second opinion process. These panels are a collaborative process between four institutions (originally three, Southampton Solent University, Southampton University, Portsmouth University and now joined by Winchester University) and four local authorities; Hampshire, Isle of Wight, Portsmouth and Southampton.

Alongside the panel process the University of Portsmouth has asked selected students to undertake presentations to increase their understanding of the issues, add clarity to the decision making process where there are areas of doubt and promote outcomes for individual students. The early presentations took place some 10 years ago and we have built on and refined the process over time.

81 J. of Practice Teaching \& Learning 11(1), pp.80-88. DOI: 10.1921/ 175951511X651931. @ wEbb 


\section{Practice consultation panel process}

The practice consultation panel process is called upon when a student experiences difficulties in placement in a similar way to the use of a second opinion practice teacher. They are used where a student is potentially failing a practice placement or experiencing difficulty in the placement setting. The policy has been drawn up and agreed by all agencies and universities offering social work training within our region. Initially the practice learning co-ordinators from each of these agencies and universities aimed to keep a specified day free each month in case a panel was required. Recently this has been changed to give each university a different day each month. There are a variety of reasons for this including increasing student numbers and the clash of demand when more than one university requires a panel within any specific month. The panel comprises of practice learning co-ordinators or experienced practice teachers or tutors from the region. A minimum panel would comprise one member from an agency and a tutor from a different university where the staff have no prior knowledge of the placement. These panels report to the practice assessment panel and university unit and award boards and can refer an individual for the consideration of invoking the termination of training process.

Over the years the panels considering issues for students have asked for the students to review particular areas, and these students are now brought back to the panel for a final decision. Not all students are asked to undertake presentations, the main reasons are when there are areas of doubt around the students understanding of an issue or the lack of clarity regarding whether the student had the full opportunity to learn in a placement. It is important to note that the main area of concern that has given rise to the use of presentations stems from issues around the English National Occupational Standards key roles 5 (Manage and be accountable, with supervision and support, for your own social work practice within your agency) and 6 (Demonstrate professional competence in social work practice) (TOPSS, 2002) and the GSCC codes of practice.

\section{Presentation patterns}

From the early stages of setting presentations, during the years of the DipSW a number of presentations have been set for most students. This has

82 J. of Practice Teaching \& Learning 11 (1), pp.80-88. DOI: 10.1921/ 175951511X651931. @ w\&b 
generally been following an issue in placement but they have also been used prior to placement where questions around fitness to practice have been evident. The titles for presentations are generated to increase the abilities of the students in terms of their reflective thinking. In a study by Lam, Wong and Leung, (2007) it was found that 'disturbing events experienced by students in their fieldwork were a catalyst to their reflective process' (p.91), and this has been borne out by our experience. Having to attend a practice consultation panel can trigger this disturbance as the student faces the possibility of not reaching their goal of becoming a social worker.

For some students where a single presentation has been used, this is usually related to a smaller or more specific area of difficulty or question that has been raised for the panel. One example of this would be where the student has progressed well apart from a single, but significant, incident of inappropriate boundaries.

Many students have been set a series of presentations that build on each other to cover the issues that have arisen. One example that has been used was

- Professional accountability - how to behave as an accountable professional;

- What is the meaning of professional assertiveness?

- The conflicts and tensions within the values and ethics underpinning social work;

- Developing reflective skills - revisiting the placement experience.

An analysis of recent years shows that just under $20 \%$ of students referred to practice consultation panels have been asked to undertake presentations prior to progressing and/or decisions about progression. The outcome for those students involved over the most recent academic years up to and including 2009-10 is within the table below.

Table 1

Portsmouth University Practice Consultation Panel outcomes following presentations

\begin{tabular}{lcl}
\hline Student & No. of presentations & Outcomes \\
\hline A & 3 & Repeat placement-student withdrew \\
B & 3 & Progress to placement \\
C & $1+4$ & Repeat placement \\
D & 4 & Repeat placement \\
E & 4 & Termination/transfer to academic award \\
F & 4 & Repeat placement \\
\hline
\end{tabular}

83 J. of Practice Teaching \& Learning 11(1), pp.80-88. DOI: 10.1921/ 175951511X651931. @ wEbb 
The style of presentations is agreed and guidance provided. Students are expected to use PowerPoint for their presentation. The PowerPoint is helpful as it provides a framework for the student, can allow for other panel members to be copied into the basics of each presentation for further consideration and can be sent to external examiners for their consideration. The students are expected to introduce their topic, cover the relevant theory, reflect on the links between the topic and the issues that arose for them in practice and summarise their learning. This could equate to assisting students through the CODE process as proposed by Lomax, Jones, Leigh and Gay, (2010). This lists the stages of problem solving for students on placement as

Consider - the problem through analysis, defining the problem and reflecting on your situation.

Options - available to you to change your situation

Decide - what action to take

Evaluate the changes made. (p.118)

A set of dates is provided for the student with the list of titles. The pattern has varied from weekly for most students to monthly for students where time will not impact on the progression (for example, they have an academic unit to complete and are in a resit year) All presentations are observed by at least two people. This can be the personal tutor, practice learning co-ordinators from the university or occasionally panel members from practice where this is possible. The student is asked to prepare material for a 15-20 minute presentation and the panel then have an opportunity to ask questions of the student. The questions will aim to elicit areas that have been missed during the formal presentation, or probe areas of concern. The students are provided with some initial verbal feedback at the end of each session, and fuller written feedback follows.

\section{The agency perspective}

Very often the process of referring to Practice Consultation Panel (PCP) is a challenging one for both students and others involved in the process. Work by Bird \& Ambler (2005) highlights the issues for students, assessors and work base supervisors where failing students create a variety of feelings that need to be managed in order to engage successfully with the process

84 J. of Practice Teaching \& Learning 11 (1), pp.80-88. DOI: 10.1921/ 175951511X651931. @ w\&bb 
of panel. For agencies the bottom line relates to the impact of the student on service users and how they ensure that service users are protected. There is often an ongoing impact from student involvement that may have repercussions for those continuing to work with service users who may be vulnerable.

As a local authority the use of presentations as part of an outcome from the panel process has been valuable in a variety of ways. Firstly, the student can be seen in a different setting using tools to present their own views and ideas on a particular subject that enables those observing to better gauge learning and its links to the placement experience. This is key to the process; as the student is no longer in the placement they have dedicated time to reflect critically on the placement experience and how this has impacted on their learning. From this, those observing are able to identify much more clearly (in partnership with the student) links to key roles 5 and 6 where most concerns are raised. This then enables students to continue making links to other presentations if there are any and to the new placement experience if subsequently offered.

Secondly, it provides another level of assessment that practice assessors are reassured by given the stressful effects of failing a student. The independence of the panel provides reassurance to the student as well as objectivity in the process.

It is essential that if a new placement is identified that all those involved in the process are aware of the learning that has occurred so that it can be used to support the student as part of their ongoing development. By the same token the process has sometimes provided clear evidence of the student's inability to develop and learn and supported some to recognise that social work is not for them.

There is a commitment required by those people who are part of a PCP panel to be part of the group who observe the student presentations as this provides some element of continuity as well as enabling discussion linked to the evidence presentations provide. In this authority this is seen as an essential role for the agency practice learning coordinator. There are implications for smaller independent organisations if they are not able to afford the time for participation in presentations but this has not appeared as a major issue for this process thus far.

It would be fair to say that the use of presentations as an outcome from the PCP is considered a more effective way of assessing a student's ability to analyse and reflect on the placement experience outside of the formal panel subject to the acknowledgement of particular learning styles. This 
gives credibility to the process and also reassures an agency that the student has been seen and assessed by others in addition to those from the university setting.

\section{Discussion}

The process of using presentations has developed over time and has had many benefits. It must be noted that there may be potential difficulties and this should be guarded against and reviewed periodically. Whilst presentations provide a wealth of material, they may also be less successful for students with particular learning styles or needs.

For many students there have been key issues regarding reflective abilities, and frequently issues linked to the evidencing of professional development and the Codes of Practice. This has been linked to a weaker understanding of self and the innate prejudices they may hold. The presentation system is supported by tutorials from the allocated academic tutor and allows these areas to be explored and developed.

This system aims to improve the start point for a further placement should this be offered. The process of preparing the material for presentations improves their understanding of the issues and areas of concern. Whilst giving the students what may be viewed as additional work this should aid the progression of the students who complete this task. Progression of students is a key factor for universities, and the profession, but the maintaining of professional standards is paramount.

Using presentations could be viewed as one way of working with students identified as at risk of non-progression. There are issues linked to progression with poorer rates of progression for particular groups such as men, people from ethnic minority groups and people with disabilities as evidenced through the work of Hussein, Moriarty, Manthorpe and Huxley, (2007). There are similarities with this work in terms of the proportion of students being referred into the system and our experience is that using individual presentations, with the increased knowledge of whether or how cultural issues may be impinging on a students progress, can promote a more successful outcome. Our programme takes a high proportion of students from the widening participation route and these students can experience a higher than average level of anxiety and insecurity when undertaking their university level study as evidenced by Jones (2006).

86 J. of Practice Teaching \& Learning 11 (1), pp.80-88. DOI: 10.1921/ 175951511X651931. @ w\&b 
There are issues of power within this use of presentations as it could be felt that this additional requirement is not negotiable however in the light of the need to gate keep a profession and ensure that our graduates will be sound practitioners for the future this requires a balance of needs. A key imperative from universities, agencies and practice educators is the need to maintain the standards and values required by the profession and the service users. Research has shown that whilst the role of practice assessors has changed a major continuity is the expectation of the level of skills required by students (Moriarty et al., 2010).

There is a body of evidence to suggest that when a student is potentially failing a high commitment is required from all involved. This was summarised in a comment from a respondent to the research undertaken by Moriarty et al. (2010) who said

by the mid point the student was failing and I arranged a 'four way' meeting (with student, self, tutor and manager).....This plan demanded a high level of commitment from all parties in addition to increased time allocation ... (p.596)

The impact on both the practice educators and the students can be devastating, and there can be impacts and ripple effects on service users, agency staff and others from the student group. Parker (2010) has undertaken a study regarding the issues of power and student perspectives when placements are disrupted and the experience of our students mirrors his work with respect to the impact of failure and the need for a student voice. The use of presentations has helped to rebalance some of these impacts for students prior to a repeat placement being arranged.

Our experience has been positive for both students and practice placements. The agency practice placement staff find this a thorough and fair process, ensuring rigour in respect to decisions regarding continuation on the professional programme and students have provided feedback ranging from 'I have learnt more from this process than the rest of the course' from a student progressing to a final placement to 'I know that I have had every opportunity to evidence my abilities' from a student who failed to complete the professional programme transferring to an alternative degree. We have also had feedback from the practice education team from previous placements of some students that has been positive as it is felt that it has ensured that lessons needed to be learnt have been reinforced. It is undoubtedly a resource intensive system, but in our view this is a worthwhile cost in terms of assisting students to progress and become accountable and safe practitioners for the future.

87 J. of Practice Teaching \& Learning 11(1), pp.80-88. DOI: 10.1921/ 175951511X651931. @ wEbb 


\section{References}

Bird, A. and Ambler, S. (2005) Creative Tools for Practice Teaching: Issues with a failing student? Course material

Barron, C. (2004) Do we need a second opinion here? Journal of Practice Teaching in Health and Social Work, 5, 2 22-38

CCETSW. (1989) Paper 30. Rules and requirements for the Diploma in Social Work. London: CCETSW

GSCC. (2002) Code of Practice for Social Care Workers. London: GSCC

Hussein, S., Moriarty, J., Manthorpe, J., and Huxley,P. (2008) Diversity and progression among students starting social work qualifying programmes in England between 1995 and 1998: a quantitative study. British Journal of Social Work, 38, 8, 1588-1609

Jones, K. (2006) Valuing diversity and widening participation: The experience of access to social work students in further and higher education. Social Work Education, 25, 5, 485-500

Lam, C,. M. Wong, H., and Leung, T.T.F. (2007) An unfinished reflexive journey: social work students' reflection on their placement experiences. British Journal of Social Work. 37, 1, 91-105

Lomax, R., Jones, K., Leigh, S., and Gay, C. (2010) Surviving your Social Work Placement. Basingstoke: Palgrave Macmillan

McColgan, M. and Douglas, H. (1995) The demise of the second opinion practice teacher: For better or for worse? Social Work Education, 14, 3, 94-8

Moriarty, J., Macintyre, G., Manthorpe, J., Crisp, B.R., Orme, J., Green Lister, P., Cavanagh, K., Stevens, M., Hussein, S., and Sharpe, E. (2010) 'My expectations remain the same. The student has to be competent to practise': Practice assessor perspectives on the new social work degree qualification in England. British Journal of Social Work. 40, 2, 583-601

Parker, J. (2010) When things go wrong! Placement disruption and termination: Power and student perspectives. British Journal of Social Work, 40, 3, 983-999

Topss England, (2002) The National Occupational Standards for Social Work. www. topssengland.net. (accessed20th December 2010)

88 J. of Practice Teaching \& Learning 11(1), pp.80-88. DOI: 10.1921/ 175951511X651931. @ wEb 